
Audu LI
Mairami AB
Mukhtar-Yola M
Otuneye AT
Tahir LM
Papka NY
Mshelia LJ
Maitala H
Igoche MI
Anyanwu PA
Jawa ZM

\section{Prune belly syndrome in a set of twins, a family tragedy: Case report}

DOI:http://dx.doi.org/10.4314/njp.v40i4,17

Accepted: 4th May 2013

\author{
Audu LI, (匹) \\ Mairami AB, Mukhtar-Yola M, \\ Otuneye A T, Tahir LM, Papka NY, \\ Mshelia LJ, Maitala H, Igoche MI, \\ Anyanwu PA, Jawa ZM \\ Department of Paediatrics, \\ National Hospital Abuja \\ Email:drauduli@yahoo.com
}

\begin{abstract}
We report prune belly syndrome, a rare congenital malformation, in a set of twins delivered to a young couple with a history of three previous first trimester spontaneous abortions, discordant HIV seropositivity and antenatal ultrasound report that indicated renal abnormalities in
\end{abstract}

only one of the twins. The challenges of management are discussed.

Keywords: Prune Belly Syndrome, Twins, Nigeria, Management challenges

\section{Introduction}

Prune Belly Syndrome (PBS), a rare congenital malformation presenting at birth with a triad of abdominal muscle deficiency, urinary tract abnormalities and cryptorchidism ${ }^{1}$ has rarely been reported in multiple gestations. The incidence varies from 1:35,000-1:50,000 live births and only $4 \%$ of cases are products of twin pregnancies. The first documented case occurring in both live born monozygotic twins was in 2000 by Balaji et al. ${ }^{2}$ Although a few cases of PBS have been reported from Nigeria, ${ }^{3,4,5,6}$ our report is the first documented occurrence of PBS in twin gestation in Nigeria. Antenatal diagnosis in developing countries may be limited by unavailability of radiologic facilities and expertise, often compounded by failure of pregnant mothers to attend antenatal clinics, while financial constraints affect the extent to which postnatal evaluation can be conducted. The success of surgical treatment (abdominoplasty, bilateral orchiopexy and urinary tract reconstruction) ${ }^{7}$ in carefully selected patients is a function of prompt and comprehensive diagnostic work up.

This communication highlights the diagnostic and management challenges encountered in a set of twins with Prune Belly Syndrome delivered at the National Hospital Abuja.

\section{Case Report}

This set of male twin babies were born at the National Hospital Abuja, via elective caesarean section at a gestational age of 34 weeks. The initial part of her antenatal care was at a private hospital from where she was referred to the National Hospital to access care for retroviral infection. Her last CD4 count done shortly before delivery was 228 cells $/ \mathrm{mm}^{3}$. Although there was no family history of congenital malformations, the index pregnancy was preceded by three successive spontaneous first trimester abortions.

During the course of her antenatal visits at the National Hospital Abuja, she had three obstetric ultrasound scans and each reported the presence of renal malformations in one fetus while the second fetus was consistently, reportedly normal. Findings in both babies at birth included lax anterior abdominal wall, bilateral flank fullness, palpable kidneys and undescended testes on the basis of which a diagnosis of PBS was made (figure 1). Apart from talipes equino varus deformity in the first twin, other findings were essentially normal. They had good Apgar scores, weighed $2.93 \mathrm{~kg}$ and $3.07 \mathrm{~kg}$ respectively at birth and were not in respiratory distress.

The initial serum electrolytes (E), urea (U) and creatinine $(\mathrm{Cr})$ revealed elevated potassium and creatinine levels. Abdominopelvic ultrasound revealed bilateral hydronephrosis with completely thinned out 
renal parenchyma. Serial E, U, Cr showed deteriorating renal function in both twins and intravenous urogram (IVU) was therefore considered unsafe. A radionuclide renogram was conducted and this showed poorly functioning kidneys with bilateral vesico-ureteric reflux in both twins.

Fig 1: A set of male twins with Prune Belly Syndrome

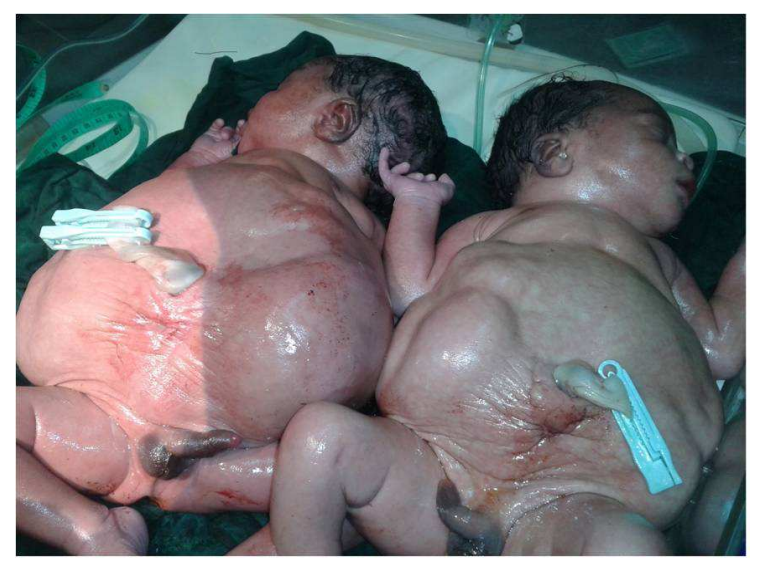

The discoloration on one of the twins resulted from reflection of light from the overhead radiant warmer

They received intravenous fluids, antibiotics and Nevirapine (Anti Retroviral Viral prophylaxis). Bilateral loop ureterostomy for urinary diversion was done on the fifth day of life following which there was some improvement in renal function.

Additional treatment included top-up blood transfusions done on two occasions. The first twin also developed scrotal swelling due to hypoproteinemia during the second week of life that resolved gradually with the introduction of enteral feeds after an initial infusion of albumin. Their subsequent hospital stay was essentially uneventful. The parents were counseled and the mother was encouraged to participate in the feeding and general care of the babies.

Both babies were discharged home at the age of 24 days to be followed up in the clinic. However, the first twin died from suspected aspiration of feeds at home three days after discharge while the second twin died from a respiratory infection at the age of three months.

\section{Discussion}

The exact aetiology of PBS is unclear, however postulations on the pathogenesis of this congenital disorder include prostatic hypoplasia resulting in functional urethral obstruction ${ }^{1}$ or a basic defect of the embryonic mesoderm. ${ }^{8}$ Although sex-influenced mode of inheritance has also been postulated because of the male preponderance of the disease, this may be linked with the theory of prostatic deficiency. Our patients were both males confirming the predominant occurrence of PBS in males. The previous history of recurrent spontaneous first trimester abortions may have resulted from severe congenital malformations that were not compatible with normal intrauterine life. Ramasamy et $\mathrm{al}^{9}$ while studying 11 cases of familial PBS had suggested a sex linked autosomal pattern of inheritance. It may be tempting to speculate familial PBS in our patients, but we do not have sufficient information about the aborted fetuses to support this speculation.

Although our patients did not die in the neonatal period, their clinical presentation at birth and the progressive renal functional deterioration put them in the most severe category of PBS. ${ }^{10}$

There have been few reports of PBS in Nigeria. Okeniyi et $\mathrm{al}^{3}$ postulated reasons for the rarity and these include: low awareness, missed diagnosis at maternity centers and high rate of deliveries outside the health institutions. Twinning is said to be associated with PBS. Balaji et $\mathrm{al}^{2}$ first reported concordant PBS in a set of monozygotic twins. To the best of our knowledge, this is the first report of PBS in concordant twins from Nigeria. On the other hand, familial PBS is rarer with less than 20 cases reported worldwide. The case reported from UBTH in Nigeria occurred in a child with an affected older sibling suggesting a familial occurrence. ${ }^{5}$

The limitation of obstetric ultrasonography in the detection of congenital malformations which may be an indication of the experience of the ultrasonographer was amply demonstrated in our patients. Although it is a significant improvement over previous reports where babies were only discovered at delivery to be abnormal, the non-specificity and inadequacy of the ultrasound reports precluded any form of emergency obstetric intervention (such as bilateral nephrostomy) and appropriate preparation for neonatal care.

The presence of the classical triad of lax abdominal wall, cryptorchidism and enlarged kidneys at birth enabled immediate clinical diagnosis. The results of serial electrolytes, urea and creatinine showed progressive deterioration in renal function with some improvement when ureterostomy was done. Although it was contraindicated to carry out intravenous urography, we had the option of radionuclide renal scan which demonstrated bilateral poor renal function in both babies. It was therefore possible to prognosticate and appropriately counsel the parents.

Prognosis for patients with PBS usually depends on the state of the urinary tract at birth as well as the degree of pulmonary hypoplasia. In those with the severe form of disease, death occurs in utero or in the early neonatal period. ${ }^{10}$ Our patients presented with evidence to suggest abnormal urinary system at birth. While the first twin died in the late neonatal period, the second twin died in the immediate post neonatal period.

The inaccurate prenatal report constituted an ethical issue and also compounded parental counseling. Additionally, the long-term benefit of surgical urinary diversion despite apparent poor prognosis was difficult to justify. 
This young couple who had lost three previous pregnancies and tested positive for HIV in the index pregnancy, had hoped that they would be home with one normal baby based on the antenatal ultrasound reports. This was one tragedy too many.

\section{Conclusion}

Accurate antenatal diagnosis of PBS remains a challenge in developing countries. Clinical diagnosis at birth as well as prompt laboratory and radiologic evaluation will enable appropriate plan for management and prognostication.
Covering Letter: The undersigned authors certify that the article is original, is not under any consideration by any other journal and has not been previously published.

\section{Authors' contribution}

Audu LI, Mairami AB: Clinical management of babies and preparation of manuscript

Mukhtar-Yola M, Otuneye AT, Tahir LM, Papka NY, Mshelia LJ, Maitala H, Clinical management of babies Igoche MI, Anyanwu PA: Carried out ureterostomy on the babies

Jawa ZM: Performed radionuclide assessment on babies

Conflict of interest: None

Funding: None

\section{References}

1. Moerman P, Fryns JP, Goddeeris P, Lauweryns JM. Pathogenesis of the prune-belly syndrome: a functional urethral obstruction caused by prostatic hypoplasia. Paediatrics. 1984 Apr;73 (4): 470-5.

2. Balaji K, Patil A, Townes P, Primack W, Skare J. Concordant prune belly syndrome in monozygotic twins. Urology 2000;55:949.

3. Okeniyi JAO, Ogunlesi TA, Dedeke IOF, Oyelami OA, Oyedeji GA. Prune Belly Syndrome in a Nigerian child. Internet J Pediatr Neonatol 2005;5:2.

4. Adeyokunnu AA, Familusi JB. Prune belly syndrome in two siblings and a first cousin, possible genetic implications. Am J Dis Child 1982; 136: 23-25.
5. Ibadin MO, Ademola AA, Ofoewe GE. Familial Prune Belly Syndrome in a Nigerian Family. Saudi J Kidney Dis Transpl 2012; 23 (2): 338-342.

6. Adekanmbi A.F, Fetuga M.B, Ogunlesi T.A, Ogundeyi M.M, Gbadebo F, Oyinlade A. Prune Belly Syndrome in Sagamu: Report of Three cases with Typical and Atypical Features. Niger J Paediatr 2006; 33:(1)22-25.

7. Denes FT, Arap MA, Giron AM, Silva FA, Arap S. Comprehensive surgical treatment of prune belly syndrome; 17 years' experience with 32 patients. Urology 2004 Oct; 64(4): 789-93.
8. Stephens FD, Gupta D. Pathogenesis of the prune belly syndrome. $J$ Urol. 1994 Dec; 152 (6 Pt 2): 2328 -31 .

9. Ramasamy R, Haviland M, Woodard JR, Barone JG. Patterns of inheritance in familial prune belly syndrome. Urology 2005; 65:1227.

10. Woodhouse CRJ, Ransley PG, Innes-Williams D. Prune belly syndrome- report of 47 cases. Arch Dis Child 1982; 57:856-859.

11. Mehta BJ, Patel SV, Bansal A, Barot B, Nair SV, Damor PB, Shah KD. Prune Belly Syndrome. Gujarat Med J 2010 Feb; 65(1):71-72. 